\title{
Avances en tomografía de coherencia óptica y endomicroscopía confocal láser en enfermedades pulmonares
}

\author{
Annika W.M. Goorsenberg Kirsten A. Kalverda Jouke T. Annema Peter I. Bonta \\ Departamento de Pulmonología, Centros Médicos de la Universidad de Ámsterdam, Universidad de Ámsterdam, \\ Ámsterdam, Países Bajos
}

\section{Palabras Clave}

Tomografía de coherencia óptica · Endomicroscopía confocal láser · Enfermedad pulmonar obstructiva · Broncoscopía · Cáncer de pulmón · Enfermedad pulmonar intersticial

\section{Resumen}

El diagnóstico y monitoreo de enfermedades pulmonares depende en gran medida de los estudios de imagen, las pruebas de función fisiológica y la toma de muestras de tejido. La tomografía de coherencia óptica (TCO) y la endomicroscopía confocal láser (ECL) son técnicas de imagen novedosas con resolución casi microscópica, que pueden combinarse de manera fácil y segura con la broncoscopía convencional. Mediante estas técnicas pueden visualizarse compartimentos anatómicos pulmonares relacionados con enfermedades, en tiempo real. En enfermedades pulmonares obstructivas, pueden identificarse y cuantificarse las capas en las paredes de las vías respiratorias y el remodelado estructural asociado. En neoplasias pulmonares, es posible discriminar entre áreas normales y malignas en las vías respiratorias centrales, el parénquima pulmonar, los nodos linfáticos y la pleura. Un número creciente de enfermedades pulmonares intersticiales (EPIs) han podido visualizarse mediante TCO o ECL. Es posible estudiar por imagen va- rios cambios estructurales asociados con EPIs: fibrosis, infiltración celular, bronqui(ol)ectasias, quistes y el patrón microscópico en panal de abejas. Aunque aún no se han implantado en la práctica clínica, la TCO y la ECL tienen el potencial de mejorar la detección y el monitoreo de enfermedades pulmonares y pueden contribuir a desentrañar la fisiopatología de varias enfermedades y el mecanismo de acción de nuevos tratamientos. De hecho, el examen de las paredes de las vías respiratorias mediante TCO podría ser útil al evaluar tratamientos contra el remodelado de las vías respiratorias. Al visualizar células malignas individuales, la ECL tiene potencial como herramienta para detectar el cáncer en tiempo real. En el futuro, ambas técnicas podrían combinarse con la detección de marcadores fluorescentes con láser. Esta revisión discute el valor de la TCO y la ECL en la medicina pulmonar, presentando de forma sumaria la evidencia actual, y se comentan las perspectivas a futuro. C 2020 El (los) autor(es). Publicado por S. Karger AG, Basilea

\section{Introducción}

El diagnóstico de enfermedades pulmonares depende en gran medida de técnicas de imagen como la tomografía computarizada torácica de alta resolución (TCAR) o procedimientos mínimamente invasivos como la broncoscopía para la toma de muestras de tejidos. Las imágenes por TCAR contribuyen al diagnóstico de muchas enfermedades pulmonares; sin embargo, la resolución es- pacial es limitada, y se somete a los pacientes a radiación ionizante. El muestreo endobronquial, como en las biopsias mucosales y parenquimales y la aspiración por aguja, conlleva riesgos de complicaciones, está sujeto a errores de muestreo y sólo proporciona información sobre un sitio de muestreo específico.

Sería útil contar con imágenes de resolución mayor a la TCAR, al nivel histológico/celular, para diagnosticar y entender la fisiopatología de las enfermedades pulmonares, y para monitorear los

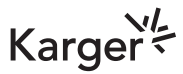

(C) 2021 The Author(s)

Published by S. Karger AG, Basel

This article is licensed under the Creative Commons AttributionNonCommercial-NoDerivatives 4.0 International License (CC BYNC-ND) (http://www.karger.com/Services/OpenAccessLicense) Usage and distribution for commercial purposes as well as any distribution of modified material requires written permission. 


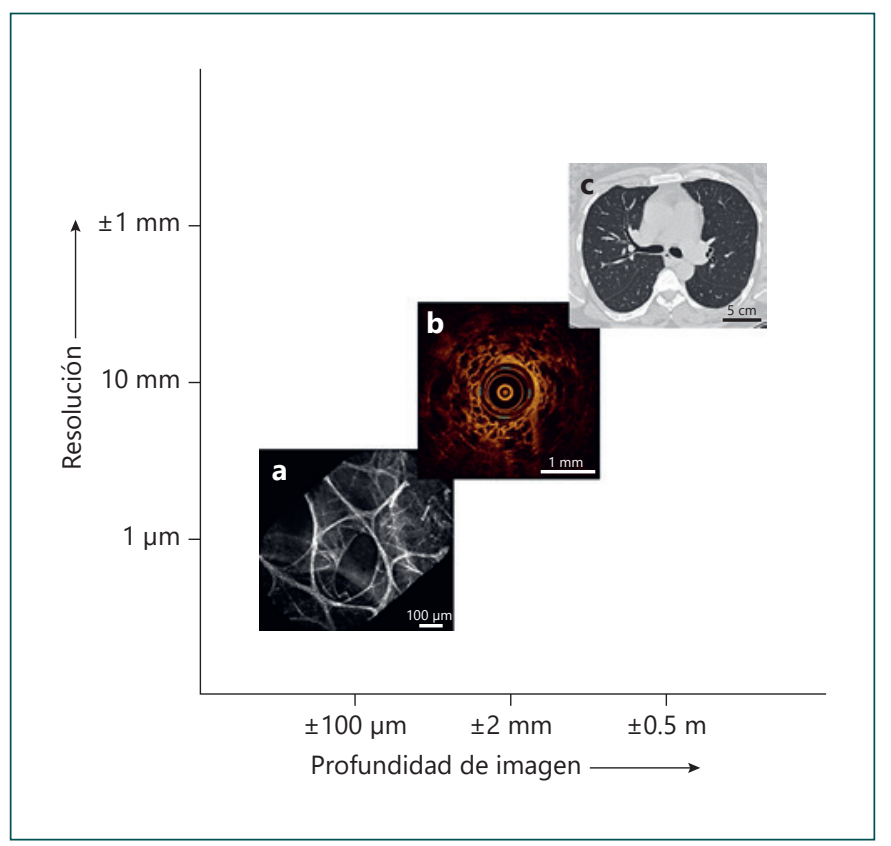

Fig. 1. Técnicas de imagen aplicadas al compartimento alveolar, con la resolución y profundidad de imagen correspondientes. a ECL. b TCO. c TRAC torácica.

tratamientos. La tomografía de coherencia óptica (TCO) y la endomicroscopía confocal láser (ECL) son dos técnicas de imagen novedosas que pueden llenar la laguna entre el muestreo selectivo e invasivo de tejido y la resolución limitada de la TCAR. Todas estas técnicas son complementarias: muestran desde un panorama del pulmón (TCAR) hasta imágenes casi microscópicas (ECL; Fig. 1). En esta revisión discutimos el valor de la TCO y la ECL broncoscópicas en enfermedades pulmonares, presentando en forma sumaria los estudios de imagen basados en TCO y ECL en los compartimentos anatómicos relacionados con enfermedades pulmonares obstructivas, neoplasias en el pulmón y enfermedades pulmonares intersticiales (EPIs; Fig. 2, Tabla 1). Asimismo, se discuten aplicaciones clínicas potenciales de estas técnicas de imagen en el manejo de enfermedades pulmonares (Tabla 1). La aplicabilidad de la TCO en enfermedades pulmonares vasculares se describió en una revisión publicada previamente, y se discute de manera más breve [1].

\section{Antecedentes técnicos}

\section{Tomografía de coherencia óptica}

La TCO es una técnica de imagen que emplea luz en el infrarrojo cercano para generar imágenes de estructuras tisulares, con una resolución de $\pm 10-15 \mu \mathrm{m}$ y una profundidad de 2-3 mm (Fig. 1) $[2,3]$. La idea conceptual de la TCO es comparable al ultrasonido, pero en vez de emplear la reflexión de ondas acústicas, la TCO utiliza la dispersión de luz en el infrarrojo cercano para generar imágenes. Una ventaja de la TCO sobre el ultrasonido endobronquial (radial) es que las ondas luminosas no necesitan un medio transductor o contacto directo con el tejido, y por tanto tiene ex- celentes propiedades para emplearse en compartimentos anatómicos llenos de aire, como las vías respiratorias. En pocas palabras, en la TCO, un haz luminoso genera luz en el infrarrojo cercano y se enfoca en el tejido. La diferencia en el tiempo para que la luz se disperse de regreso en las estructuras se mide y se compara con un haz de referencia, aplicando los principios de la interferometría óptica. Esto permite al sistema de TCO generar imágenes transversales en 2D (Fig. 2, 3). Posteriormente, las imágenes $2 \mathrm{D}$ consecutivas generadas por retroceso de la sonda pueden reconstruirse en estructuras 3D. Aunque se exploran muchas aplicaciones en la medicina, inicialmente la TCO se adoptó en oftalmología para obtener imágenes de la retina [4-6]. Además, la TCO se emplea actualmente para evaluar la estenosis y la aposición de stents en las arterias coronarias en las intervenciones cardiológicas [7-10]. La TCO no se ha adaptado clínicamente aún para propósitos pulmonares. Sin embargo, en la última década, diversos estudios han mostrado que la aplicación de la TCO en la medicina pulmonar es factible, segura y ofrece beneficios para una amplia gama de indicaciones (Tabla 1). Los estudios incluidos en esta revisión que investigan el uso de la TCO en la medicina pulmonar han empleado ya sea sondas fabricadas por compañías (St. Jude Medical Inc., Abbott, IL, EE. UU.; Pentax Corp., Tokio, Japón; escáner luminoso-CTTM, LLTech, Francia; LightLab Imaging Inc., Westford, EE. UU.; Niris Imaging System, Imalux Corp., Cleveland, OH, EE. UU.) o dispositivos construidos ex profeso. Las imágenes por TCO de las vías respiratorias o del compartimento alveolar se capturan durante la broncoscopía (Fig. 3ac). El catéter de la TCO se inserta a través del canal de trabajo de un broncoscopio y se hace avanzar hasta alcanzar la región de interés. Posteriormente, mediante retroceso manual o automatizado, el catéter genera una secuencia de imágenes transversales de segmentos del compartimento anatómico de interés, incluyendo las vías respiratorias, el parénquima pulmonar y las arterias pulmonares (Fig. 3, Tabla 1). En esta revisión se resumen los avances que la TCO ha permitido, al mejorar el diagnóstico y el manejo de enfermedades pulmonares obstructivas, neoplasias y EPIs.

\section{Endomicroscopía confocal láser}

La ECL es una técnica de imagen, compatible con la broncoscopía, toracoscopía e intervenciones transtorácicas con aguja [11], que proporciona imágenes en tiempo real de las vías respiratorias, los alveolos, tumores pulmonares, la pleura y los nódulos linfáticos, con una resolución de hasta $3.5 \mu \mathrm{m}$, una profundidad máxima de $70 \mu \mathrm{m}$ y un campo de visión máximo de $600 \mu \mathrm{m}$ (Fig. 1, 2). Una sonda de fibra óptica se hace avanzar a través del canal de trabajo de un broncoscopio, un toracoscopio o una aguja, y se dirige al área de interés, donde ilumina al tejido con luz láser (488 nm es la longitud de onda más común). La luz reflejada se redirecciona de regreso a través de un orificio. Solamente la luz que esté exactamente en foco pasará por el orificio, lo que produce imágenes con alta resolución. Al mover el haz de láser vertical u horizontalmente podemos reconstruir imágenes 3D mediante un software especial. En la literatura, la ECL se denomina en ocasiones microscopía de fluorescencia confocal, microendoscopía confocal o alveo-
Kompass Neumol 2021;3:3-13 DOI: $10.1159 / 000514332$ 
Tabla 1. Estudios de imagen en humanos que emplean TCO y ECL en medicina respiratoria

\begin{tabular}{|c|c|c|c|c|}
\hline $\begin{array}{l}\text { Enfermedades } \\
\text { pulmonares }\end{array}$ & $\begin{array}{l}\text { Compartimento } \\
\text { anatómico }\end{array}$ & Tomografía de coherencia óptica (TCO) & Endomicroscopía confocal láser (ECL) & Potenciales implicaciones clínicas a futuro \\
\hline $\begin{array}{l}\text { Enfermedades } \\
\text { pulmonares } \\
\text { obstructivas }\end{array}$ & $\begin{array}{l}\text { Pared de la vía } \\
\text { respiratoria }\end{array}$ & $\begin{array}{l}\text { Asma } \\
\text { - Detección de MLVR [42] y grosor de la } \\
\text { pared de la vía respiratoria [40] } \\
\text { - Evaluación de suficiencia de la vía } \\
\text { respiratoria por medición del lumen de la vía } \\
\text { a diferentes presiones [39] } \\
\text { - Efectos (agudos) de la TB: abombamiento } \\
\text { del epitelio [41], edema en la pared de la vía } \\
\text { respiratoria [40, 41] } \\
\text { EPOC } \\
\text { - Evaluación del lumen y el grosor de la } \\
\text { pared de la vía respiratoria en diferentes } \\
\text { etapas de EPOC [35, 36, 38] } \\
\text { - Evaluación de suficiencia de la vía } \\
\text { respiratoria por medición del lumen de la vía } \\
\text { a diferentes presiones [39] }\end{array}$ & $\begin{array}{l}\text { Asma } \\
\text { - del patrón de fibras de elastina en la pared de la } \\
\text { vía respiratoria [17] } \\
\text { EPOC } \\
\text { - Visualización del patrón de fibras de elastina en } \\
\text { la pared de la vía respiratoria [47] } \\
\text { - Detección y cuantificación de enfisema [48] }\end{array}$ & $\begin{array}{l}\text { - Evaluación del remodelado de la vía } \\
\text { respiratoria, incluyendo componentes } \\
\text { estructurales de la vía respiratoria como } \\
\text { parte de una fenotipificación extensa en } \\
\text { enfermedad obstructiva de las vías } \\
\text { respiratorias } \\
\text { - Evaluación del efecto de tratamientos } \\
\text { contra el remodelado de la vía respiratoria } \\
\text { (p. ej. termoplastia bronquial, inmunoterapia) } \\
\text { - TCO combinada con láser para la } \\
\text { detección de trazadores marcados con } \\
\text { fluorescencia }\end{array}$ \\
\hline \multirow[t]{4}{*}{ Neoplasias } & $\begin{array}{l}\text { Pared de la vía } \\
\text { respiratoria }\end{array}$ & $\begin{array}{l}\text { Cáncer pulmonar } \\
\text { - Detección de lesiones endobronquiales } \\
\text { neoplásicas y no-neoplásicas [50-55] }\end{array}$ & $\begin{array}{l}\text { Cáncer pulmonar } \\
\text { - Detección de lesiones endobronquiales } \\
\text { neoplásicas y no-neoplásicas }[16,58,60,61]\end{array}$ & $\begin{array}{l}\text { - Mejora de la detección temprana del } \\
\text { cáncer pulmonar } \\
\text { - Mejora del rendimiento diagnóstico de los } \\
\text { procedimientos broncoscópicos para } \\
\text { diagnosticar cáncer pulmonar }\end{array}$ \\
\hline & $\begin{array}{l}\text { Nódulos } \\
\text { linfáticos } \\
\text { mediastinales }\end{array}$ & $\begin{array}{l}\text { Cáncer pulmonar } \\
\text { - Identificación de neoplasias en nódulos } \\
\text { linfáticos (ex vivo) [57] }\end{array}$ & $\begin{array}{l}\text { Cáncer pulmonar } \\
\text { - Identificación de células malignas en nódulos } \\
\text { linfáticos }[25,26]\end{array}$ & $\begin{array}{l}\text { - Mejora del rendimiento diagnóstico de la } \\
\text { estadificación endosonográfica en el cáncer } \\
\text { pulmonar } \\
\text { - Diferenciación de nódulos linfáticos } \\
\text { neoplásicos (subtipos), granulomatosos y } \\
\text { reactivos }\end{array}$ \\
\hline & Pleura & - & $\begin{array}{l}\text { Lesiones pleurales } \\
\text { - Diferenciación entre fibrosis pleural y } \\
\text { mesotelioma [11] } \\
\text { - Visualización de lesiones malignas durante la } \\
\text { toracoscopía [66] } \\
\text { Efusión pleural } \\
\text { - Identificación de células malignas en efusión } \\
\text { pleural [67] }\end{array}$ & $\begin{array}{l}\text { - Guía para alcanzar lesiones (malignas) } \\
\text { - Diferenciación entre lesiones benignas y } \\
\text { malignas }\end{array}$ \\
\hline & $\begin{array}{l}\text { Parénquima } \\
\text { pulmonar }\end{array}$ & $\begin{array}{l}\text { Cáncer pulmonar } \\
\text { - Identificación de nódulos malignos (ex } \\
\text { vivo) [56] }\end{array}$ & $\begin{array}{l}\text { Cáncer pulmonar } \\
\text { - Identificación de nódulos malignos: } \\
\text { ex vivo }[63] \text { e in vivo }[22,59,62]\end{array}$ & $\begin{array}{l}\text { - Mejora del rendimiento diagnóstico de la } \\
\text { aspiración con aguja } \\
\text { - Herramienta de guía para biopsias } \\
\text { transbronquiales y transtorácicas }\end{array}$ \\
\hline $\begin{array}{l}\text { Enfermedades } \\
\text { pulmonares } \\
\text { intersticiales }\end{array}$ & $\begin{array}{l}\text { Parénquima } \\
\text { pulmonar }\end{array}$ & $\begin{array}{l}\text { EPI } \\
\text { - Características del TCO: engrosamiento/ } \\
\text { pérdida de estructura de red alveolar } \\
\text { (fibrosis), patrón en panal de abejas, quistes y } \\
\text { bronquiectasias }[54,71-73]\end{array}$ & $\begin{array}{l}\text { EPI } \\
\text { - Características de la ECL en EPI [83, 84] } \\
\text { - Detección de fibrosis [83-85] } \\
\text { - Identificación de rechazo agudo de trasplante de } \\
\text { pulmón [81, 82] }\end{array}$ & $\begin{array}{l}\text { - Discriminación de EPI fibrótica contra } \\
\text { celular } \\
\text { - Guía para ubicación óptima de biopsia en } \\
\text { EPI } \\
\text { - Detección temprana de rechazo a } \\
\text { trasplante }\end{array}$ \\
\hline $\begin{array}{l}\text { Enfermedades } \\
\text { vasculares } \\
\text { pulmonares }\end{array}$ & $\begin{array}{l}\text { Vasculatura } \\
\text { pulmonar }\end{array}$ & $\begin{array}{l}\text { Hipertensión arterial pulmonar } \\
\text { - Estructura de la arteria pulmonar: media } \\
\text { [87] e íntima engrosada (fibrosis) [88, 89] } \\
\text { Hipertensión pulmonar tromboembólica } \\
\text { crónica } \\
\text { - Oclusión trombótica, bandas/redes } \\
\text { luminales [87, 89] } \\
\text { - Visualización de los efectos de la APG [92] } \\
\text { - Distinción entre trombos agudos y crónicos } \\
\text { [94] }\end{array}$ & - & $\begin{array}{l}\text { - Diferenciación entre diferentes formas de } \\
\text { HP, p. ej. HAP y HPTEC } \\
\text { - Determinación de la ubicación de } \\
\text { remodelado arterial pulmonar dentro del } \\
\text { sistema arterial pulmonar } \\
\text { - Evaluación de los efectos de tratamientos } \\
\text { contra HAP en el remodelado arterial } \\
\text { pulmonar }\end{array}$ \\
\hline
\end{tabular}

Resumen de la literatura sobre TCO y ECL, categorizada por enfermedad pulmonar y subcategorizada por compartimento anatómico. Todos los estudios se realizaron en laboratorios de investigación y se hicieron in vivo, a menos que se especifique lo contrario. La implantación de las técnicas en la práctica clínica estándar no ha ocurrido aún. TCO, tomografía de coherencia óptica; ECL, endomicroscopía confocal láser; MLVR, músculo liso de las vías respiratorias; TB, termoplastia bronquial; EPOC, enfermedad pulmonar obstructiva crónica; EPI, enfermedad pulmonar intersticial; APG, angioplastia pulmonar con globo; MAC, matriz extracelular; HP, hipertensión pulmonar; HAP, hipertensión arterial pulmonar; HPTEC, hipertensión pulmonar tromboembólica crónica.

loscopía. En este trabajo utilizamos el término ECL para esta técnica de imagen. Cuando la sonda de ECL se combina con una aguja (en donde la sonda de ECL se hace avanzar a través de una aguja hueca), se emplea el término «ECL con aguja» (nECL). El término «ECL con sonda» (pECL) se refiere a la técnica en la que la sonda de ECL se hace avanzar hacia el tejido, omitiendo directamente la necesidad de una aguja (Fig. 4).
La mayor parte de la evidencia para la aplicación de la ECL en la práctica clínica proviene de enfermedades gastrointestinales, por ejemplo, en la detección de neoplasias en el esófago $[12,13]$ y de quistes pancreáticos [14]. En enfermedades no-malignas, como colitis ulcerativa, se ha demostrado que la ECL es superior a cualquier otra modalidad de imagen para evaluar la curación de la mucosa [15]. 


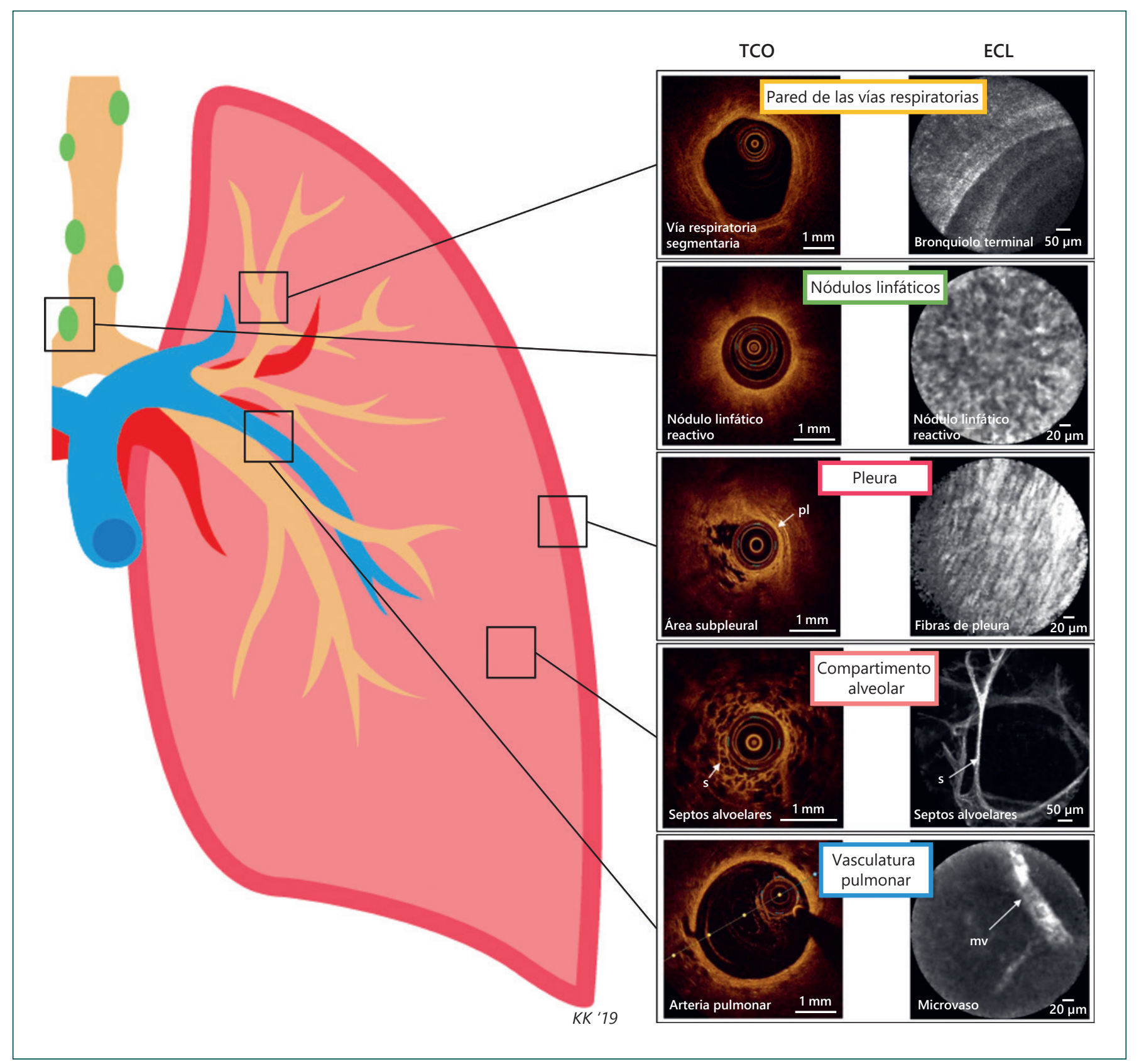

Fig. 2. Esquema de los compartimentos anatómicos del pulmón con las correspondientes imágenes por TCO y ECL. Pared de las vías respiratorias: TCO, vista transversal de la pared de las vías respiratorias en una vía respiratoria segmentaria; ECL, imagen por pECL que muestra un patrón anillado helicoidal típico en un bronquiolo terminal. Nódulos linfáticos: TCO, imagen en un nódulo linfático reactivo; ECL, imagen por nECL que muestra abundantes linfocitos en un nódulo linfático reactivo. Pleura: TCO, imagen del área subpleural, la pleura está señalada por una flecha blanca; ECL, fibras de elastina organizadas en forma laminar en la pleura, como se observa mediante pECL. Compartimento alveolar: TCO, vista transversal del compartimento alveolar con una red de septos alveolares; ECL, imagen por pECL que muestra septos alveolares con espacios aéreos rectangulares. Vasculatura pulmonar: TCO, vista transversal desde la arteria pulmonar; ECL, imagen por nECL de un microvaso en un nódulo linfático.

Los primeros reportes del uso in vivo de pECL en el tracto respiratorio humano se remontan a 2007. Los estudios iniciales mostraron la factibilidad de obtener imágenes de la pared de las vías respiratorias y demostraron que las imágenes obtenidas por pECL dependen de la presencia de fibras de elastina, que es autofluorescente a la luz láser de $488 \mathrm{~nm}[16,17]$. Puesto que la elastina constituye la base de los componentes estructurales en el compartimento alveo- lar, incluyendo los septos alveolares y los microvasos [18-20], así como de la pleura, éstos pueden visualizarse in vivo, en tiempo real, mediante pECL. Adicionalmente, es posible obtener imágenes por autofluorescencia de algunos componentes celulares, incluyendo células inflamatorias como los macrófagos alveolares [21].

Actualmente, hay disponible comercialmente un sistema de ECL para enfermedades pulmonares (Sistema de Endomicroscopía 


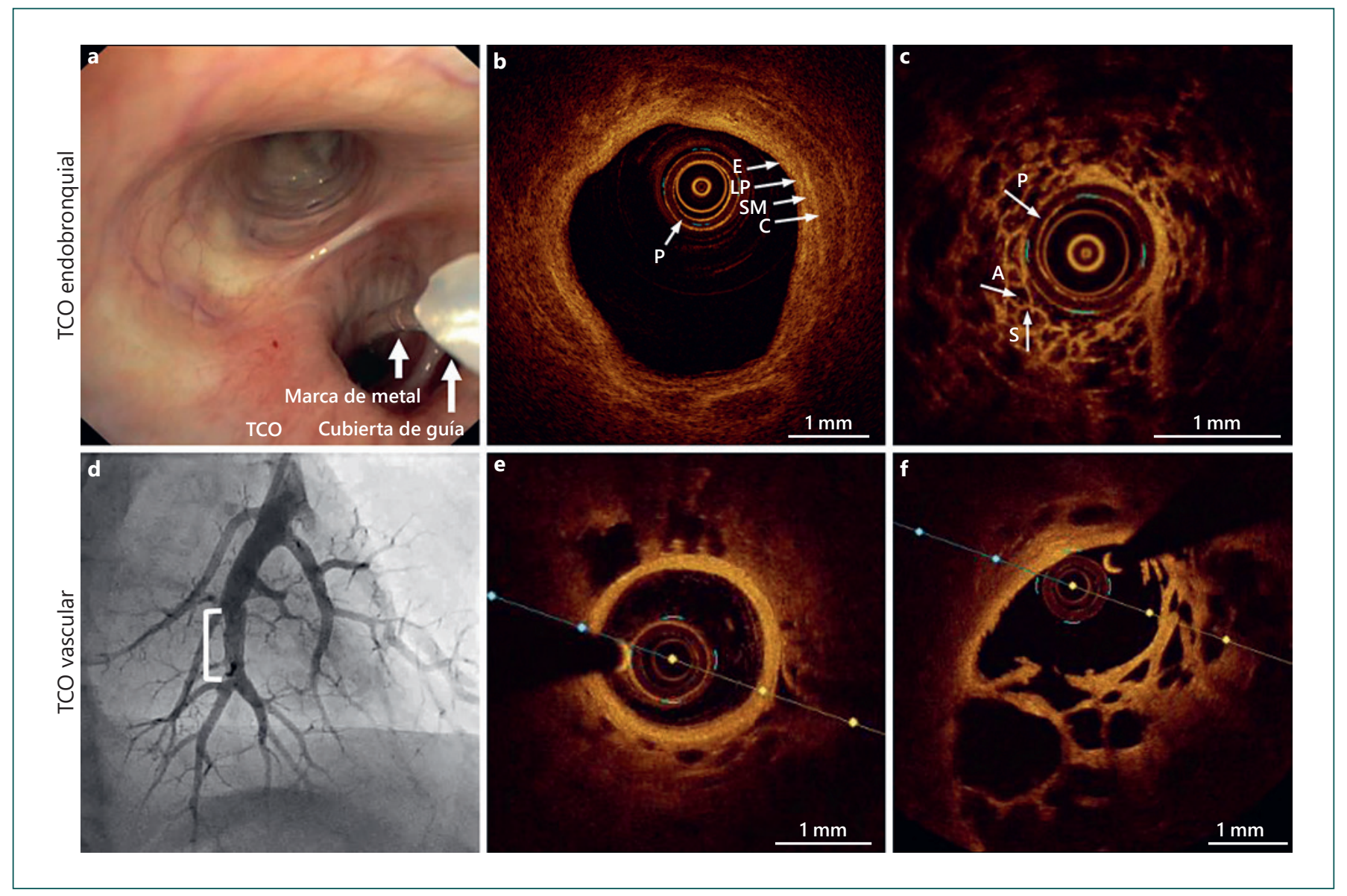

Fig. 3. Procedimientos de imagen por TCO de la pared de la vía respiratoria y el compartimento alveolar (TCO endobronquial, a-c) y la arteria pulmonar (TCO vascular, d-f). a Vista broncoscópica de un procedimiento de imagen por TCO, que muestra el recubrimiento guía y el catéter de TCO posicionados en el lóbulo inferior derecho. La marca de metal guía la distancia de $5.4 \mathrm{~cm}$ al extremo distal del catéter de TCO. b Imagen por TCO de la pared de una vía respiratoria segmentaria, que muestra la identificación de las capas en la pared de la vía respiratoria. c Imagen por TCO del compartimento alveolar, que muestra alveolos y septos normales. d Angiografía de la arteria pulmonar del lóbulo inferior derecho, con estenosis, en un paciente con hipertensión pulmonar tromboembólica crónica (HPTEC; corchete blanco). e Imagen por TCO de una arteria pulmonar proximal normal. f Imagen por TCO de una arteria pulmonar con redes/bandas en un paciente con HPTEC (imágenes proporcionadas por H.J. Bogaard, MD, PhD; N. van Royen, MD, PhD, y M. Beijk, MD, PhD). TCO, tomografía de coherencia óptica; P, sonda; A, espacio alveolar; S, septos; E, epitelio; LP, lamina propria; SM, submucosa; C, cartílago.

Cellvizio, Mauna Kea Technologies, París, Francia). Para pECL, una minisonda compatible con un canal de trabajo de $1.9 \mathrm{~mm}$ (Alveoflex ${ }^{\mathrm{TM}}$ ) puede utilizarse para visualizar todos los segmentos del árbol bronquial y el parénquima pulmonar (Fig. 2). Sin embargo, cuando se desea alcanzar los lóbulos superiores (los segmentos apical y posterior), puede ser aconsejable usar una sonda más delgada y flexible [22].

No se requiere tinción adicional para obtener imágenes de los bronquios y el compartimento alveolar con pECL. Los estudios no han mostrado ventaja en el uso de fluoresceína para visualizar las células epiteliales. De hecho, se ha reportado que la visualización de los alveolos se reduce al emplear fluoresceína, debido a la aparición de una sustancia espumosa [23, 24].

Para obtener imágenes de masas en los pulmones o los nódulos linfáticos puede emplearse la técnica de ECL con aguja. Para este propósito, la sonda confocal más delgada (AQ-flex ${ }^{\mathrm{TM}}$ ) se hace avanzar a través de una aguja de calibre 19. A diferencia de la pECL en el tracto respiratorio, debe administrarse fluoresceína disódica intravenosa. La fluoresceína permite visualizar células individuales, al mejorar la fluorescencia del trasfondo estromal. Las células individuales no se tiñen con fluoresceína, lo que produce una imagen negativa, donde las células aparecen como puntos oscuros contra un fondo brillante (Fig. 4f). Distintas estructuras anatómicas en los nódulos linfáticos pueden identificarse con la nECL. La cápsula, con fibras de elastina autofluorescentes, puede distinguirse de la corteza, en la que pueden identificarse las células linfoides (Fig. 4), así como los folículos linfoides, que aparecen como grandes discos oscuros $[25,26]$.

\section{Enfermedades pulmonares obstructivas}

\section{Tomografía de coherencia óptica}

Las enfermedades pulmonares obstructivas, como el asma y la enfermedad pulmonar obstructiva crónica (EPOC), se caracterizan por el remodelado de las vías respiratorias, que incluye cambios estructurales y engrosamiento de la pared de las vías respira- 

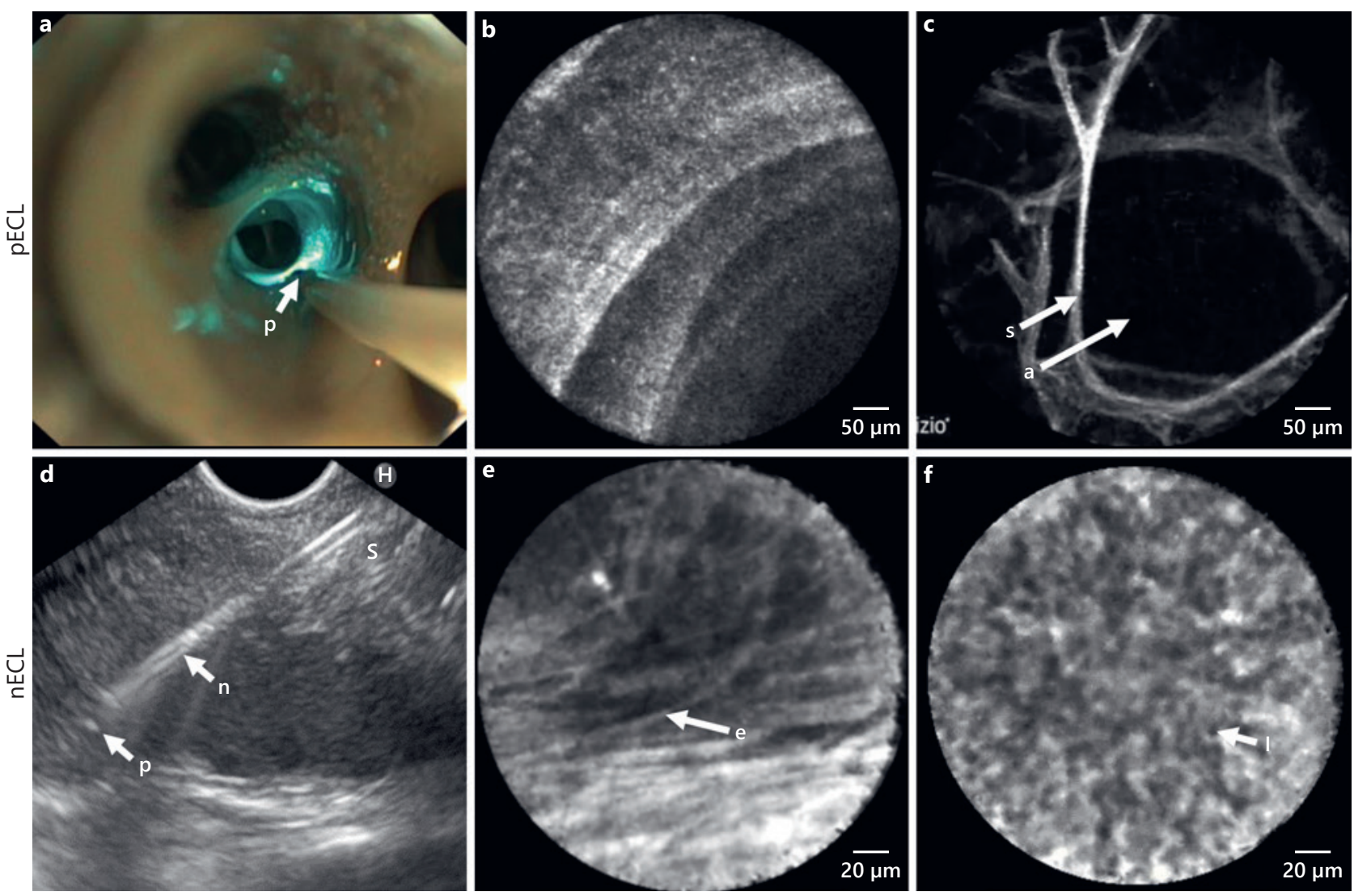

Fig. 4. Procedimientos de imagen por pECL in vivo con las correspondientes imágenes del compartimiento alveolar normal y de la pared de la vía respiratoria (a-c); imagen por nECL in vivo con las correspondientes imágenes de la cápsula y la corteza de un nódulo linfático reactivo (d-f). a pECL con la sonda (p) posicionada en las vías respiratorias centrales del lóbulo inferior derecho durante su avance hacia el compartimento alveolar. Luz láser de 488 nm reflejándose en la pared de la vía respiratoria (azul). b imagen por pECL de la pared distal de la vía respiratoria, mostrando el patrón en anillo helicoidal del bronquiolo terminal. c imagen por pECL del compartimento alveolar, mostrando alveolos llenos de aire (a) y septos alveolares (s). $\mathbf{d} n E C L$ durante un procedimiento de endosonografía (USE) para estadiaje de cáncer pulmonar, con la sonda (p) extendiéndose $2 \mathrm{~mm}$ desde la punta de la aguja (n). e imagen por nECL mostrando las fibras de elastina (e) de la cápsula de un nódulo linfático. f imagen por nECL mostrando linfocitos (I) en un nódulo linfático reactivo (Wijmans et al. [85]). pECL, endomicroscopía confocal láser con sonda; s, septos; a, espacio alveolar; nECL, endomicroscopía confocal láser con aguja.

torias [27-29]. Junto con la inflamación, el remodelado de las vías respiratorias es una característica fisiopatológica clave en el asma, y se relaciona con la gravedad del padecimiento. Por tanto, es importante desarrollar herramientas precisas para evaluar el remodelado de la pared de las vías respiratorias [30]. La TCO se considera una técnica prometedora para evaluar el remodelado de las vías respiratorias en enfermedades pulmonares obstructivas, porque exhibe una alta correlación con los estudios histológicos para la identificación (Fig. 3c) y la cuantificación de las capas de la pared de las vías respiratorias, tanto en estudios en animales [31] como en las vías respiratorias humanas [32-34].

El valor de la TCO se ha confirmado con varios estudios, donde las imágenes por TCO de la pared de las vías respiratorias se correlacionan con la TCAR y con parámetros de la función pulmonar. Coxson et al. [35] han comparado las imágenes por TCAR y por TCO en una cohorte de 44 fumadores y exfumadores, y mostraron una fuerte correlación con el grosor de la pared de las vías respiratorias. Adicionalmente, en ese estudio se midió el volumen espiratorio forzado en un segundo $\left(\mathrm{VEF}_{1}\right)$ y se le correlacionó con el grosor de la pared de las vías respiratorias de quinta generación, medida tanto por TCAR como por TCO, y la TCO mostró la correlación más fuerte. Esta correlación entre el $\mathrm{VEF}_{1}$ y las vías respiratorias se confirmó en otro estudio, en el que se incluyó a pacientes con EPOC en varios estadios, y se encontró una alta correlación entre las dimensiones de la pared de las vías respiratorias medidas por TCO y el estadiaje basado en el $\mathrm{VEF}_{1}$ [36]. En pacientes con asma alérgica, el cociente $\mathrm{VEF}_{1} / \mathrm{CVF}$ se correlacionó con el grosor epitelial y el abombamiento de la mucosa medidos por TCO, un método con buen potencial para evaluar la broncoconstricción [37]. Asimismo, en un estudio que empleó la oscilometría de impulso, una prueba de la función pulmonar que aplica ondas sonoras para evaluar la resistencia respiratoria, se encontró una correlación entre las áreas de la pared de las vías respiratorias pequeñas (de séptima a novena generación) medidas con TCO y la resistencia respiratoria en fumadores crónicos y pacientes con EPOC [38]. Adicionalmente, la TCO puede utilizarse para evaluar 

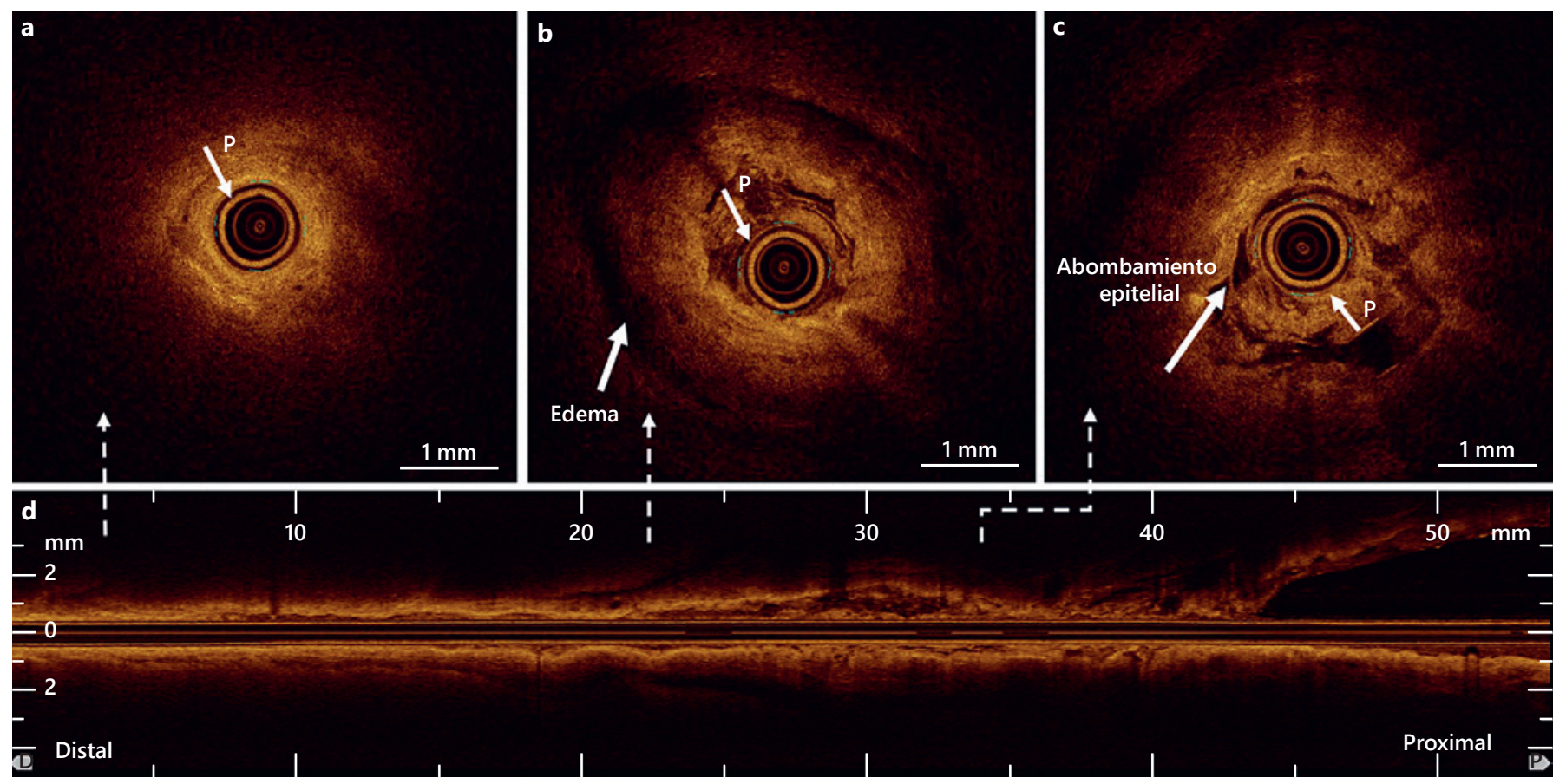

Fig. 5. Imágenes por TCO del segmento anterior (LB3) del lóbulo superior izquierdo directamente después del tratamiento con termoplastia bronquial (TB). a área distal normal, no tratada directamente con TB, de las vías respiratorias. b Área de las vías respiratorias con edema peribronquial, tratada con TB. c Área de las vías respiratorias tratada con TB, mostrando abombamiento epitelial. d Reconstrucción correspondiente de la vía respiratoria por retroceso de la sonda (540 imágenes 2D, longitud total $5.4 \mathrm{~cm}$; Goorsenberg et al. [41]). P, sonda.

las propiedades elásticas de la pared de las vías respiratorias cuando se combina con métodos de presión aumentada en las vías respiratorias [39]. Además de evaluar el remodelado de las vías respiratorias en pacientes con enfermedades pulmonares obstructivas, la TCO puede contribuir a desentrañar el mecanismo de acción de nuevas técnicas de tratamiento y a evaluar la respuesta al tratamiento. La TCO se empleó en un estudio piloto de dos pacientes con asma grave, para evaluar el efecto de la termoplastia bronquial (TB) en la pared de las vías respiratorias hasta dos años después del tratamiento [40]. Aunque los dos pacientes incluidos en este estudio mostraron signos clínicos de asma y mediciones espirométricas similares, sólo un paciente respondió a la TB. La TCO se utilizó para explorar las diferencias entre estos dos pacientes, y reveló un epitelio engrosado, probablemente inflamado, en el paciente no-respondedor, mientras que la pared de las vías respiratorias en el paciente con buena respuesta se hallaba engrosada, pero sin signos de inflamación. Asimismo, después de la TB se describió una diferencia: en el paciente respondedor, el grosor total de la pared de las vías respiratorias disminuyó, mientras que en el no-respondedor permaneció sin cambios. Estos resultados sugieren que la TCO podría ser útil en la identificación de las características iniciales para una selección óptima de pacientes candidatos a TB. En el asma grave, la TCO también se ha utilizado para evaluar los efectos agudos de la TB en la pared de las vías respiratorias, y con ella se identificaron patrones en esa pared, incluyendo abombamiento epitelial y edema (Fig. 5). Es interesante señalar que los efectos agudos de la TB se extendieron a las vías respiratorias menores distales, no tratadas; esto sugiere que el tratamiento tam- bién puede afectar las vías respiratorias menores en pacientes asmáticos graves [41].

Aunque es posible detectar diferentes capas de la pared de las vías respiratorias con TCO, medir manualmente las capas toma mucho tiempo y es difícil identificar las diferentes estructuras y componentes dentro de estas capas, como las proteínas de la matriz extracelular (MEC; p. ej., colágeno) o el músculo liso de las vías respiratorias (MLVR). Mediante la adición de una plataforma birrefringente al sistema de TCO, Adams et al. [42] identificaron y cuantificaron automáticamente fibras de MLVR en tres pacientes asmáticos y tres controles sanos, y encontraron una diferencia significativa en el grosor de las fibras de MLVR entre estos dos grupos.

\section{Endomicroscopía confocal láser}

La visualización de las vías respiratorias utilizando pECL se basa en las fibras de elastina en la MEC subepitelial. En los bronquios pueden identificarse cinco patrones diferentes, dependiendo de la profundidad de la sonda en el árbol bronquial [16]. Es posible observar desde fibras de elastina densas y unidireccionales, con una glándula bronquial ocasional que se abre en el bronquio principal proximal, hasta fibras sueltas, orientadas transversalmente, e incluso fibras dispuestas en forma de red en las vías respiratorias menores, distales; el bronquiolo terminal muestra un patrón en anillo helicoidal (Fig. 4). En pacientes con asma, se ha descrito que las fibras de elastina aparecen reducidas o fragmentadas [43]. Sin embargo, en un estudio sobre imágenes por pECL en pacientes asmáticos y controles sanos, se reportó que un patrón laminar denso se asoció con un $\mathrm{VEF}_{1}$ menor [17]. En EPOC, hasta donde 
sabemos, sólo un estudio ha tomado imágenes de las vías respiratorias con ECL. De los diferentes patrones de elastina subepiteliales, se ha descrito que los pacientes con EPOC muestran una distribución más suelta de las fibras de elastina, en vez de patrones de fibras laminares o mixtos, con respecto a fumadores sin EPOC y voluntarios sanos. Ello posiblemente indica la destrucción de las fibras de elastina en la MEC de la pared de las vías respiratorias en los pacientes con EPOC, en coincidencia con un estudio histológico previo publicado por Black et al. [44].

En el compartimento alveolar, algunos estudios en animales han mostrado una correlación entre el enfisema pulmonar y la presencia de espacios aéreos agrandados con capilares más delgados, junto con una pérdida de densidad capilar $[45,46]$. Esta correlación se reprodujo in vivo utilizando pECL en pacientes con EPOC, sin necesidad de biopsia. Más aún, se demostró que los pacientes con EPOC tienen una intensidad de autofluorescencia menor en los septos alveolares con respecto a voluntarios sanos, indicando potencialmente la destrucción de estos septos, formados por elastina [24, $47,48]$. Aunque la pECL muestra hallazgos específicos en pacientes con EPOC, aún es necesario establecer el valor agregado de la pECL sobre la TC torácica estándar y las pruebas de función pulmonar.

\section{Neoplasias}

\section{Tomografía de coherencia óptica}

La detección de tejido canceroso en el pulmón es sumamente importante para propósitos de diagnóstico y estadiaje, así como para la evaluación de los márgenes en el tratamiento quirúrgico del cáncer pulmonar. Varios grupos han investigado el uso de TCO en otras especialidades oncológicas, principalmente en dermatología, urología y gastroenterología [49].

La presencia de neoplasias pulmonares en diferentes compartimentos anatómicos puede evaluarse por imagen mediante TCO, incluyendo neoplasias endobronquiales de las vías respiratorias centrales, masas o nódulos en el parénquima pulmonar y metástasis en los nódulos linfáticos.

Se han publicado resultados prometedores en la identificación de tumores endobronquiales, tanto in vivo [50-52] como ex vivo [5255]. En estos tumores endobronquiales, un estudio identificó diferentes características para tres subtipos de cáncer: carcinomas de células escamosas, adenocarcinomas y carcinomas poco diferenciados [55]. Tres revisores recibieron entrenamiento para identificar estos criterios en una cohorte de 82 muestras de tumor ex vivo, y mostraron una exactitud promedio de $82.6 \%$ (rango, 73.794.7\%). Hasta donde sabemos, no se han publicado estudios que investiguen el valor de la TCO en la evaluación de los márgenes en el tejido tumoral extirpado.

En masas y nódulos pulmonares, así como en metástasis a los nódulos linfáticos, un uso potencial de la TCO es la obtención de imágenes por TCO con aguja durante la aspiración transbronquial con aguja. Un grupo de investigación llevó a cabo un estudio en nódulos pulmonares, con alta sensibilidad y especificidad (ambas >95\%) para la diferenciación ex vivo entre nódulos pulmonares y tejido parenquimal sano [56]. El mismo grupo de investigación estudió el uso de TCO para identificar metástasis en los nódulos linfáticos. Se practicó TCO con aguja en 26 nódulos linfáticos ex vivo, tanto sanos como con enfermedad metastásica [57]. Las características de la enfermedad metastásica fueron distintas que las de nódulos linfáticos sin cáncer, e incluso mostraron rasgos relacionados con el subtipo de tumor. Ninguna de ambas aplicaciones de TCO con aguja en nódulos pulmonares y linfáticos se ha validado in vivo aún.

\section{Endomicroscopía confocal láser}

Varios estudios han mostrado que la pECL es capaz de identificar el área anormal en neoplasias de ubicación endobronquial [16, 5861] y parenquimal (tanto cáncer de pulmón primario como metástasis) $[58,62,63]$. Usando pECL para obtener imágenes de lesiones endobronquiales, Filner et al. [61] mostraron que es capaz de diferenciar entre tejido normal y lesiones neoplásicas, y entre tejido normal y lesiones no-neoplásicas. En un estudio que incluyó 112 pacientes con un nódulo pulmonar periférico, la pECL fue capaz de detectar el área anormal en 92\% de los casos [64]. Por otra parte, Sorokina et al. [63] mostraron la presencia de un patrón específico de distelectasia alveolar, edema e influjo de macrófagos en nódulos malignos en 18 especímenes de lobectomía. Adicionalmente, el examen histopatológico por pECL confirmó los rasgos distintivos del adenocarcinoma, el carcinoma de células escamosas y el carcinoma microcítico. Sin embargo, en un estudio realizado por Seth et al. [64] se obtuvieron imágenes mediante pECL de 91 pacientes con nódulo pulmonar periférico, y aun cuando en $92 \%$ de los casos se identificó el área anormal, la pECL no fue capaz de discriminar entre lesiones benignas y malignas. Se estima que esto se debe a la dificultad para teñir células epiteliales de la mucosa bronquial [16, $59,63,64]$. A diferencia de la mucosa del tracto gastrointestinal, la fluoresceína no penetra en la capa epitelial de los bronquios [23, 24]. La administración tópica de acriflavina ha mostrado alta sensibilidad y especificidad para visualizar células malignas en tumores con ubicación endobronquial; sin embargo, su uso está a discusión por sus potenciales propiedades carcinogénicas [60].

Una estrategia alternativa, en donde el nódulo se punciona con una aguja combinada con ECL, podría resolver el problema de la tinción del tejido epitelial bronquial. En 2016, Wijmans et al. [65] presentaron un caso de cáncer pulmonar no-microcítico en el que se obtuvieron imágenes del tumor primario mediante nECL en combinación con fluoresceína intravenosa. Mientras todos los estudios sobre nódulos pulmonares periféricos mencionados hasta ahora han utilizado la pECL, Wijmans et al. [65] mostraron un caso en el que el tumor primario se visualizó con nECL combinada con USE. Los agregados celulares grandes y oscuros que aparecen en las imágenes de nECL fueron compatibles con las células malignas de adenocarcinoma. Después se realizó un estudio utilizando nECL en tumores primarios de localización central $(n=$ 6) y nódulos linfáticos sospechosos de metástasis $(n=21)$. Se propusieron tres características para predecir la malignidad: células agrandadas, pleomórficas, cúmulos grandes y corrientes direccionales. Estos criterios se validaron prospectivamente para de terminar la malignidad de los tumores o nódulos linfáticos, con una exactitud diagnóstica de 90\% [26] (Fig. 6).
10

Kompass Neumol 2021;3:3-13 DOI: $10.1159 / 000514332$ 

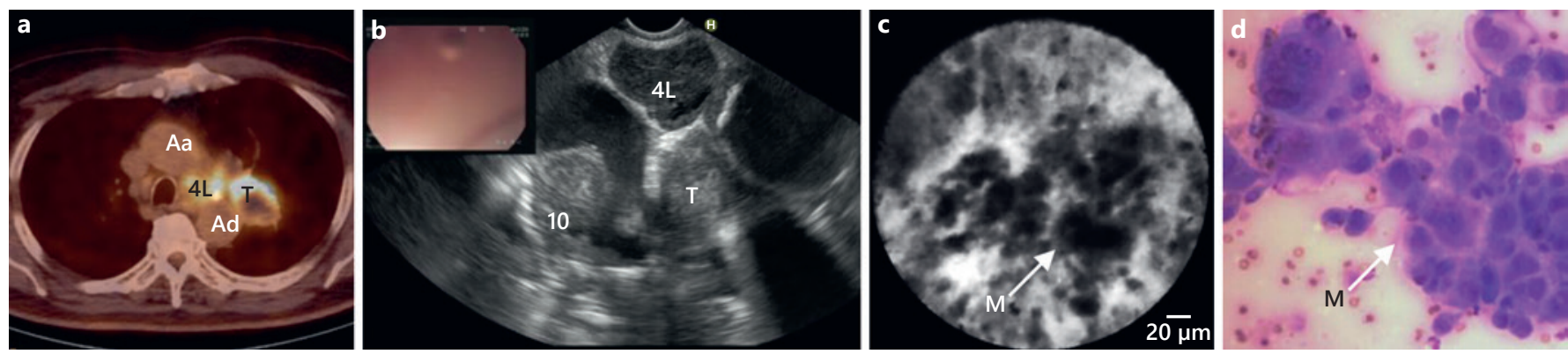

Fig. 6. nECL guiada por endosonografía de la metástasis a un nodo linfático mediastinal de un tumor en el lóbulo superior izquierdo. a Imagen exploratoria por TC-PET, mostrando una estación linfoidal $4 \mathrm{~L}$ ávida de fludesoxiglucosa, y el tumor pulmonar primario (T) b Imagen por USE que muestra nódulos linfáticos agrandados en la estación 4 L. c Imagen por nECL en tiempo real de la estación linfoidal 4 L mostrando células pleomórficas agrandadas y grandes cúmulos, reconocidos como células malignas (M). d Aspirado con aguja fina, mostrando células malignas de carcinoma de células escamosas (Wijmans et al. [26]). 10, estación linfoidal $10 \mathrm{~L}$ (izquierda); Aa, aorta ascendente; Ad, aorta descendente.

En lesiones pleurales, se ha usado tanto la pECL como la nECL para detectar células malignas. Bonhomme et al. [66] reportaron tres casos con imágenes de la pleura obtenidas mediante pECL. Se presentaron tres imágenes diferentes de la pleura: pleura normal, pleura con metástasis de cáncer pulmonar no-microcítico y un caso de mesotelioma. Las imágenes por pECL de la pleura mostraron una clara capacidad para diferenciar una pleura normal de otra neoplásica en estos casos. Poco después, se emprendió un estudio más amplio, utilizando tanto pECL como nECL para distinguir al mesotelioma maligno de áreas con fibrosis pleural. Se identificaron las características de diferentes lesiones pleurales y se validaron prospectivamente en 105 biopsias pleurales de 15 pacientes, con una moderada concordancia entre observadores [11]. En el caso de efusión pleural maligna, un estudio ex vivo encontró una alta sensibilidad y especificidad para la neoplasia pleural de la pECL en la efusión pleural [67].

\section{EPIs y otras enfermedades del parénquima pulmonar}

\section{Tomografía de coherencia óptica}

La TCO se ha usado principalmente para evaluar anormalidades en las vías respiratorias debidas tanto a enfermedades obstructivas de las vías respiratorias y neoplasias (endobronquiales). Sin embargo, recientemente se investigó el uso de TCO para evaluar el compartimento alveolar [68-70]. El valor agregado de las imágenes de alta resolución, casi microscópicas, en comparación con la TCAR, es especialmente evidente en las EPIs. En 2013, Hariri et al. [54] compararon los resultados histológicos de muestras de pulmón humano con imágenes de dominio de frecuencia óptica en cuatro pacientes ex vivo. Se identificaron características de fibrosis en estas imágenes por TCO. Más recientemente, se publicaron los primeros resultados de diagnóstico in vivo de fibrosis pulmonar idiopática en humanos por TCO [71-73]. Estos resultados mostraron que la TCO alveolar es capaz de identificar patrones microscópicos en panal de abeja, mientras que el patrón en panal de abeja radiológico no fue visible en TCAR [71]. Asimismo, se identificaron características de EPIs fibróticas como el engrosamiento de los septos alveolares y la pérdida de estructura alveo- lar, el patrón microscópico en panal de abejas, la presencia de quistes y la bronqui(ol)ectasia mediante TCO [71-73].

\section{Endomicroscopía confocal láser}

Puesto que la EPI es un padecimiento localizado en el compartimento alveolar, se ha empleado ECL para visualizar la EPI in vivo. Las imágenes de un compartimento alveolar normal muestran septos alveolares delgados con forma redonda, helicoidal o en bucle, dependiendo del ángulo de penetración de la unidad alveolar (Fig. 2, 4). Es posible visualizar los microvasos; típicamente son más gruesos que el septo alveolar, y pueden aparecer ramificados. En fumadores, pueden encontrarse macrófagos altamente fluorescentes por todo el alveolo, y esto se correlaciona positivamente con el número de cigarrillos consumidos [21]. Adicionalmente, la intensidad fluorescente de las estructuras alveolares varía: conforme aumenta la edad, los pacientes tienden a mostrar señales fluorescentes más fuertes en las fibras de elastina alveolares [21, 24]. El primer reporte del uso de la ECL en una EPI fue un caso de proteinosis alveolar pulmonar, en el cual se identificaron in vivo estructuras globulares altamente fluorescentes, compatibles con el material lipoproteico en el lavado broncoalveolar. Se describieron hallazgos similares en una serie de seis pacientes con proteinosis alveolar pulmonar [74]. Posteriormente, se publicaron reportes de casos de EPI inducida por amiodarona, microlitiasis alveolar pulmonar, aspergilosis invasiva, neumonía por Pneumocystis jirovecii, linfangioleiomiomatosis y calcificación pulmonar metastásica [75-80].

Además de lo anterior, se ha estudiado la aplicación de la ECL en la vigilancia del rechazo celular agudo (RCA) en receptores de trasplante de pulmón. Dos estudios se han enfocado en el uso de la pECL en estos pacientes, y encontraron ciertas características asociadas con el RCA. Yserbyt et al. [81] mostraron en 2014 la correlación entre el RCA un incremento en la presencia de células alveolares autofluorescentes. Este hallazgo fue confirmado por Keller et al. [82] en 2019, con el añadido de una distribución perivascular de las células. La celularidad perivascular se correlacionó significativamente con el RCA.

Se han realizado varios estudios para identificar características específicas en imágenes por pECL en EPIs. Meng et al. [83] iden- 

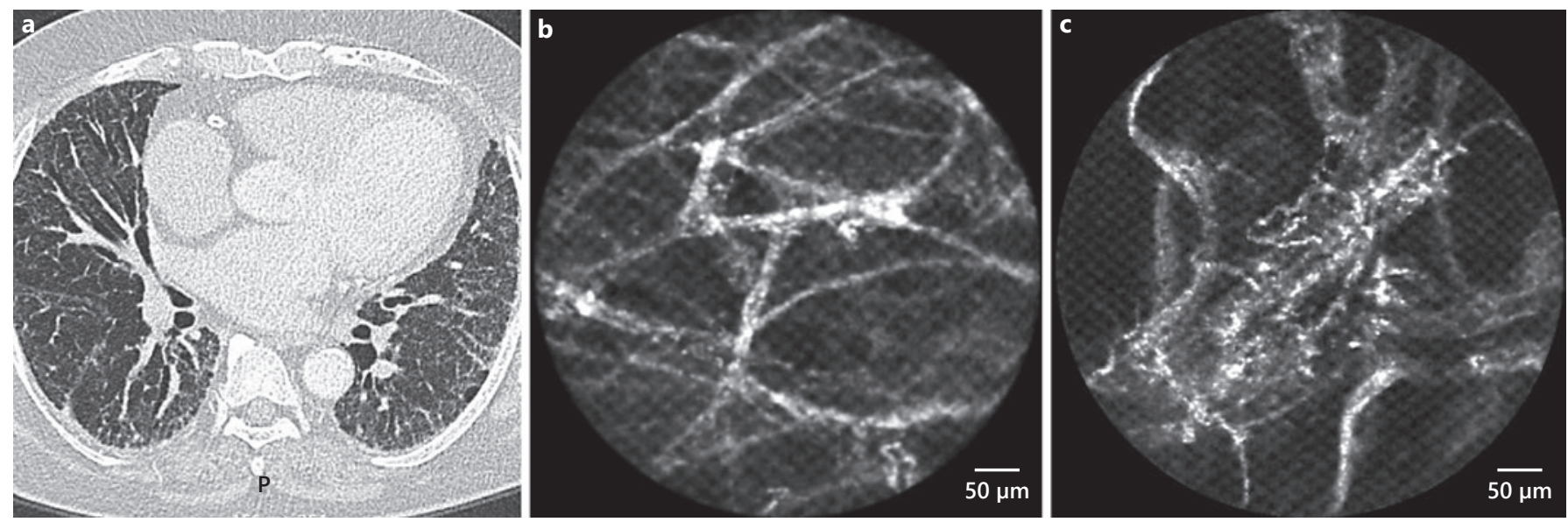

Fig. 7. Imágenes por pECL del compartimento alveolar en un paciente con NINE de tipo fibrótico. a Imagen por TCAR que muestra reticulación difusa y

bronqui(ol)ectasia. b Imagen por pECL que muestra un incremento en la densidad de red intacta de fibra de elastina alveolar. c Imagen por pECL que muestra un incremento en la densidad de red engrosada de fibra de elastina alveolar, con pérdida de la arquitectura normal (Wijmans et al. [85]). P, sonda.

tificaron seis patrones diferentes para discriminar una EPI fibrosante crónica de otras EPIs. Salaün et al. [84] identificó nueve características específicas de ECL empleando datos de 80 individuos (59 pacientes con EPI, 21 sujetos sanos). Con base en estas características, fueron capaces de discriminar entre pulmones normales y enfermos, y encontraron que ciertas EPIs se asociaban con un patrón celular en la ECL (la presencia de células bronquiales y alveolares fluorescentes), mientras que otras se asociaron con un patrón fibrótico en la ECL (bocas alveolares pequeñas, una red desorganizada y densa de fibras de elastina con septos engrosados). Sus resultados mostraron buena reproducibilidad en la interpretación entre observadores. En otro estudio observacional en 14 pacientes con EPI, la pECL fue capaz de detectar áreas parenquimales normales y anormales, y discriminar entre fibrosis leve y grave (Fig. 7). Adicionalmente, fue posible identificar la pleura y el espacio alveolar subpleural [85].

Con base en los estudios revisados líneas arriba, parece plausible que la pECL pueda diferenciar EPIs celulares de EPIs fibróticas; sin embargo, aún debe establecerse que la ECL pueda distinguir entre subtipos específicos de EPIs. El potencial de la ECL para identificar estos compartimentos diferentes, junto con el valor agregado de caracterizar la EPI, abre el camino para usar la ECL como una herramienta de guía para practicar (crio-) biopsias endoscópicas del pulmón.

\section{Enfermedades vasculares pulmonares}

\section{Tomografía de coherencia óptica}

El uso de TCO en enfermedades vasculares pulmonares se ha descrito ampliamente en revisiones publicadas anteriormente por nuestro grupo y otros equipos $[1,86]$. Brevemente, se ha investigado la utilidad de la TCO para caracterizar el remodelado de la pared de la arteria pulmonar en la hipertensión arterial pulmonar [87-89]. Se ha reportado que el grosor de la pared de la arteria pulmonar se correlaciona con varios parámetros hemodinámicos [90,
91]. En la hipertensión pulmonar tromboembólica crónica, la TCO fue capaz de evaluar la oclusión trombótica y las redes o bandas luminales [87, 89] (Fig. 3f); también se ha reportado que puede guiar el tamaño del globo y evaluar el efecto del tratamiento de angioplastia pulmonar con globo $[92,93]$. Adicionalmente, un estudio investigó el uso de TCO en el diagnóstico de trombos arteriales pulmonares periféricos en comparación con la angiografía pulmonar selectiva en 12 pacientes [94]. En este estudio, la TCO encontró un número significativamente mayor de trombos en los segmentos distales de las arterias pulmonares periféricas que la angiografía pulmonar selectiva. Por otra parte, la TCO fue capaz de diferenciar entre trombos «rojos» agudos y «blancos» crónicos.

\section{Endomicroscopía confocal láser}

Hasta donde sabemos, no se han publicado estudios sobre el uso de la ECL en enfermedades vasculares pulmonares.

\section{Perspectivas a futuro}

En resumen, en la medicina pulmonar, la TCO y la ECL son técnicas prometedoras para la obtención en tiempo real de imágenes de alta resolución in vivo, para visualizar compartimentos anatómicos importantes del tracto respiratorio, asociados con enfermedades. Sin embargo, a diferencia de lo que ocurre en oftalmología y cardiología, ni la TCO ni la ECL han logrado implantarse aún en la práctica clínica estándar.

En nuestra opinión, el uso de técnicas basadas tanto en la TCO como en la ECL tiene un gran potencial como guía o mejora en el rendimiento diagnóstico por su resolución casi microscópica y propiedades de tiempo real. Como ejemplo está el desarrollo de una aguja citológica con ECL o TCO integrada (las llamadas «agujas inteligentes») para guiar al sitio de la biopsia y ofrecer retroalimentación en tiempo real para la detección del cáncer pulmonar y el mesotelioma de la pleura [11].
12

Kompass Neumol 2021;3:3-13

DOI: $10.1159 / 000514332$ 
Adicionalmente, puesto que la TCO y la ECL avanzadas han mostrado el potencial del análisis citológico in situ en nódulos linfáticos sospechosos de neoplasia, parece razonable que estas técnicas también son capaces de detectar granulomas en, por ejemplo, la sarcoidosis.

El alcance de nuevas técnicas de imagen en endoscopía podría ampliarse en el futuro cercano al implantar el uso de marcadores fluorescentes. En este campo de las imágenes médicas, las técnicas ópticas se combinan con luz láser para detectar componentes marcados con fluorescencia. En la oncología, la detección de anticuerpos marcados con fluorescencia puede impulsar aún más la identificación de tumores para el diagnóstico y la estadificación del cáncer, y para la evaluación de los márgenes de un tumor. Por ejemplo, se empleó anti-CD47 marcado con fluorescencia para detectar cáncer de vejiga [95]. Se han utilizado labetuzumab y erlotinib conjugados con un marcador fluorescente para evaluar casos de cáncer colorrectal y tumores pulmonares con mutación EGFR, respectivamente, en modelos de xenotrasplante en ratón $[96,97]$. Asimismo, la pECL puede ser valiosa para evaluar el efecto de nuevos tratamientos, como lo demostró un estudio en el que se visualizaron células apoptóticas tras la administración de erlotinib en modelos animales de tumores con mutación EGFR [98]. En pacientes con asma grave, puede anticiparse que el marcaje molecular de los anticuerpos monoclinales empleados para inmunoterapia pueda ayudar a visualizar los blancos terapéuticos y la biodistribución de estos anticuerpos, con el objetivo de mejorar la selección de los pacientes para estas costosas terapias.

En el campo de las enfermedades infecciosas, se han hecho esfuerzos para visualizar directamente la presencia de patógenos. Hasta el momento, se han publicado tanto estudios in vivo como ex vivo para visualizar Aspergillus [99-101] y Staphylococcus aureus [102] en modelos animales empleando ECL.

Actualmente, analizar imágenes obtenidas por TCO o ECL es un proceso complejo y por ello requiere mucho tiempo. El desarrollo de software automatizado es esencial para la puesta en práctica de estas técnicas. La segmentación automatizada, basada en el análisis de intensidad o en técnicas de aprendizaje profundo, podrían ser muy útiles en el análisis de imágenes, y serán indispensables para una aplicación clínica más amplia. Ya se están haciendo mejoras, como la cuantificación automatizada [42] y la segmentación automatizada de moco [37, 103]. De igual manera, la investigación se halla enfocada en mejorar las técnicas, por ejemplo, mediante el uso de TCO sensible a la polarización, que no solamente muestra las capas estructurales de la vía respiratoria, sino también la distribución del tejido [104]. Esto hace posible distinguir varias estructuras en las vías respiratorias, como los componentes de la vía respiratoria (p. ej., MEC/MLVR). Adicionalmente, puede mejorarse la resolución de las imágenes por TCO mediante el uso de un endoscopio nanoóptico: un sistema de TCO convencional con una metalente integrada en el diseño [105]. Potencialmente, estas técnicas permitirán evaluar los efectos del tratamiento en las estructuras de la pared de la vía respiratoria involucradas en el remodelado de la pared, sin necesidad de tomar una biopsia. Otros factores que limitan la implantación de estas técnicas en la prác- tica clínica son la falta de ensayos de validación más extensos, el costo y la disponibilidad de los sistemas de TCO y ECL. En la actualidad, solamente se ha empleado la TCO y la ECL pulmonares en ensayos experimentales, en centros especializados y con personal experto en broncoscopía de intervención, que incluyeron cantidades relativamente pequeñas de pacientes.

\section{Conclusión}

La TCO y la ECL son técnicas complementarias para la obtención de imágenes de alta resolución, y se ha demostrado que su uso es factible y seguro en diversas enfermedades pulmonares. Ambas técnicas tienen un potencial considerable para mejorar el diagnóstico y el monitoreo de enfermedades pulmonares y sus tratamientos; sin embargo, antes de que estas técnicas puedan implantarse en la práctica clínica, se requiere realizar estudios más amplios de validación in vivo y crear software automatizado para el análisis de las imágenes.

\section{Agradecimientos}

Queremos agradecer a J. de Boer, PhD, F. Ferold, y J. Willemse por proporcionar imágenes de TCO sensible a la polarización de un paciente asmático; a H.J. Bogaard, MD, PhD, N. van Rooijen, MD, PhD, y M. Beijk, MD, PhD, por proporcionar imágenes de TCO de la vasculatura pulmonar, y a L. Wijmans por proporcionar imágenes de TCL.

\section{Declaración de ética}

Los autores no tienen conflictos éticos que declarar.

\section{Declaración de conflictos de interés}

El Departamento de Pulmonología recibió apoyo material de St. Jude Medical Inc., St. Paul, MN, EE. UU./Abbott, Illinois, y una subvención a la investigación irrestricta de Mauna Kea Technologies, París, Francia.

\section{Fuentes de financiamiento}

Ninguna.

\section{Contribuciones de los autores}

A.G., K.A.K., P.B. y J.A. contribuyeron con el concepto y el diseño de esta revisión. A.G. y K.A.K. contribuyeron igualmente con la interpretación de datos, la escritura del manuscrito y la preparación de las figuras. P.B. y J.A. supervisaron el proyecto y revisaron el manuscrito. Todos los autores aprobaron la versión final.

\section{Información sobre licencias}

Annika Goorsenberg, Kirsten A. Kalverda, Jouke Annema, Peter Bonta: Avances en tomografía de coherencia óptica y endomicroscopía confocal láser en enfermedades pulmonares. Respiration. 2020;99(3):190-205. Epub 8 de octubre de 2019. (https://doi/10.1159/000503261). ${ }^{\complement}$ Este artículo está protegido por la Licencia Internacional Creative Commons de atribución, no-comercial, sin derivados 4.0 (CC BY NC-ND) (http://www.karger.com/ Services/OpenAccessLicense). El uso y la distribución para propósitos comerciales, así como cualquier distribución de material modificado, requieren permiso por escrito.

\section{Referencias}

Las referencias están disponibles en www.karger.com/Article/Fulltext/ 000514332 . 